\title{
Circulation of Particles in a Vibrated Bed with an Inner Tube
}

Yuji Tatemoto*, Yuki Niwa, Takenari Takeshita

Department of materials Science and Chemical Engineering, Shizuoka University

3-5-1, Johoku, Naka-ku, Hamamatsu-shi, Japan

Keywords: Vibrated bed, bed height difference, circulation, inner tube, discrete element method

\begin{abstract}
The particle motion in a vibrated bed with an inner tube was simulated by the discrete element method (DEM). A height difference is observed in the vibrated particle bed between the interior and annulus of the inner tube. The bed height difference is strongly affected by the ratio of the cross section at the interior to that at the annulus of the inner tube. When the inner tube is immersed in the particle bed, the bed height difference causes the circulation of particles in the bed. The direction and velocity of particle circulation can be controlled by changing the inner tube diameter and the circulation velocity is also controlled with vibration conditions.
\end{abstract}




\section{Introduction}

A fluidized bed has been used as a particle handling method. The fluidized bed has many effective characteristics for mixing, drying, coating, and so on. The vibrated bed has also used for such processes. In the case of vibrated bed, the particles motion can be promoted without gas flow, and this is one of the merits comparing with the fluidized bed. The good mixing characteristics also make a problem, i,e, the retention time of materials is unstable in the continuous reactor or dryer. The initiation of the plug flow of the particles in the bed is also important in certain cases. Therefore, some ideas have been suggested and used in the case of fluidized bed. For example, a spouted bed and a fluidized bed with partitions are used to initiate the plug flow of particles in the fluidized bed. The initiation of the plug flow is also important in the case of vibrated bed though the examination is performed by only a few workers.

In this study, the bed height difference between the interior and annulus of an inner tube immersed in the vibrated bed is considered. This phenomenon was reported by Akiyama et al. [1]. They examined the effects of operational conditions on the bed height difference, experimentally, and they also examined the mixing characteristics in this system [2]. They set the tracer particles in a part of particle bed and the mixing characteristics of particles in the bed were examined. By the convection of particle in the vibrated particle bed, the tracer particles move in the bed. In this study, the control of particles plug flow in the vibrated bed was focused.

The numerical simulation was used to examine the particle motion in the vibrated bed. Generally, the numerical simulation is used to effectively describe the actual phenomena and elucidate the underlying mechanism of the phenomena. The operational conditions can be changed easily by the numerical simulation. The discrete element method (DEM) is one of the trajectory models [3-5], and all the forces acting on the particle, e.g., force of gravity and force of interaction between the particles, are calculated. Actually, Lu and Hisau has been 
studied the particle motion in vibrated bed by using DEM [6]. They examined the mixing characteristics of particles in the vibrated bed.

In this study, the particle motion in a vibrated particle bed with an inner tube is simulated by the DEM. As mentioned above, the bed height difference between the interior and annulus of the inner tube is observed in the vibrated bed with an inner tube. When the inner tube is immersed in the bed, it is considered that the bed height difference causes the circulation of particles in the bed. The effects of the bed height difference and the vibration conditions on the circulation velocity of particles were examined.

\section{Theory}

In the DEM simulation, the force acting on a particle is calculated and the acceleration, velocity, and displacement are subsequently determined.

\subsection{Force acting on a particle}

The force acting on a given particle is given by:

$$
m \frac{d v_{\mathrm{p}}}{d t}=f_{\mathrm{C}}-m g
$$

where $f_{C}$ is the contact force. The contact force $f_{C}$ is divided into normal $\left(f_{\text {Cnij }}\right)$ and tangential $\left(f_{\mathrm{Ctij}}\right)$ forces, and the model of the contact force is shown in Fig. 1 [4]. These two forces are calculated by using the following equations [7]:

$$
\begin{aligned}
& f_{\text {Cnij }}=\left(-k_{\mathrm{n}} \delta_{\mathrm{nij}}^{3 / 2}-\eta_{\mathrm{n}} v_{\mathrm{rij}} \cdot n_{\mathrm{ij}}\right) n_{\mathrm{ij}}, \\
& f_{\text {Ctij }}=-k_{\mathrm{t}} \delta_{\mathrm{tij}}-\eta_{\mathrm{t}} v_{\mathrm{tij}},
\end{aligned}
$$

where $\delta_{\text {nij }}$ and $\delta_{\text {tij }}$ are the normal and tangential displacements between particle $i$ and particle $j$, respectively. $k$ and $\eta$ are the spring and damping coefficients, respectively. The spring coefficients $k_{\mathrm{n}}$ and $k_{\mathrm{t}}$ are calculated from the equations based on the methods of Hertz and Mindlin and Deresiewicz [8], respectively, and these methods have been reported by 
Tanaka et al. [7]. The damping coefficient $\eta$ is also determined by using the method proposed by Tanaka et al. [7]:

Particle-Particle:

$$
\begin{aligned}
& k_{n}=\frac{\sqrt{d_{p}} E_{p}}{3\left(1-\gamma_{p}^{2}\right)}, \\
& k_{t}=\frac{2 \sqrt{d_{p}} G_{p}}{2-\gamma_{p}} \delta_{n}^{1 / 2}, \\
& \eta_{n}=a \sqrt{m k_{n}} \delta_{n}^{1 / 4} \\
& \eta_{t}=\eta_{n}
\end{aligned}
$$

Particle-Wall:

$$
\begin{aligned}
& k_{n}=\frac{4}{3}\left(\frac{1-\gamma_{p}^{2}}{E_{p}}+\frac{1-\gamma_{w}^{2}}{E_{w}}\right)^{-1} \sqrt{\frac{d_{p}}{2}}, \\
& k_{t}=\frac{2 \sqrt{d_{p}} G_{p}}{2-\gamma_{p}} \delta_{n}^{1 / 2}, \\
& \eta_{n}=a \sqrt{m k_{n}} \delta_{n}^{1 / 4} \\
& \eta_{t}=\eta_{n} \\
& G=\frac{E}{2(1+\gamma)}
\end{aligned}
$$

The following definition is used to consider the effect of sliding between the particles:

$$
\text { If }\left|f_{\text {Ctij }}\right|>\mu_{\mathrm{f}}\left|f_{\text {Cnij }}\right| \text {, then } f_{\text {Ctij }}=\mu_{\mathrm{f}}\left|f_{\text {Cnij }}\right| \frac{v_{\text {tij }}}{\left|v_{\text {tij }}\right|}
$$

where $\mu_{\mathrm{f}}$ is the coefficient of friction. The coefficient of friction $\mu_{\mathrm{f}}$ was determined from the following equation:

$$
\mu_{\mathrm{f}}=\tan \theta_{\mathrm{i}}
$$

The value of $\theta_{\mathrm{i}}$ was determined from the experiment. The glass particles were set on the acrylic resin and glass plates, and then the plates were tilted. The angle when the glass particles started to slide on the plate was defined as the angle of contact. The values of them were $33.4^{\circ}$ for glass - acrylic resin and $27.0^{\circ}$ for glass - glass in this study. 
The rotation of particle is obtained using

$$
\frac{d \omega_{\mathrm{p}}}{d t}=\frac{T}{I},
$$

where $I$ is the moment of inertia, and $\omega_{\mathrm{p}}$ is the angular velocity.

\subsection{Vibration}

A vessel placed on the particle bed moves because of the vibrations. The bed is subjected to sinusoidal vertical vibration, and the displacement $z_{\mathrm{w}}$ of the vessel are calculated by the following equations:

$$
z_{w}=A \sin (2 \pi f t),
$$

where $A$ and $f$ are the amplitude and frequency of vibration, respectively. The wall of the vessel acquires velocity owing to the vibration, and the wall behaves as a large solid for particles.

\subsection{Simulation conditions}

Fig. 2 shows the calculation area. The calculation was performed for a 3-D particle bed. The inner diameter of the vessel placed on the particle bed $D_{0}$ was fixed at $0.070 \mathrm{~m}$, while the inner diameter $D_{\mathrm{i}}$ and outer diameter $D_{\text {io }}$ of the inner tube were changed. The thickness of the inner tube was maintained constant at $3.0 \mathrm{~mm}$. The initial bed height $H_{0}$ was fixed at $0.075 \mathrm{~m}$. The distance between the bottom of the vessel and the lower edge of the inner tube is $H_{\mathrm{B}}$, and it was changed in one instance during the calculations. The conditions for calculation are listed in Table 1. Glass beads (diameter: $4.0 \mathrm{~mm}$ ) were used as the particles. The vessel and inner tube were made of acrylic resin. The time step of the calculation $\Delta t$ was $2.0 \times 10^{-6} \mathrm{~s}$.

At first, particles were set in the bed regularly, and then the calculation was started without vibration. The calculation without vibration was continued until particles were settled in the bed. After then, the calculation with vibration was started. Most of the cases, 
calculation time with vibration was $10 \mathrm{~s}$. After the calculation, the vibration was stopped and particles were settled in calculation. The bed heights were obtained after particles were settled in the bed.

\section{Experiment}

In order to confirm the validity of calculation, an experiment was performed. Fig. 3 shows the outline of the experimental apparatus. The experimental set up were the same as those in simulation conditions mentioned above. The acrylic resin column was used as a vessel of the particle bed and the acrylic inner tube was fixed onto the bed by using a clamp. The glass beads ( $4.0 \mathrm{~mm}$ diameter) were used as the particles. The vessel was put on the vibrator and only the vessel was vibrated. The vibration frequency and amplitude were controlled by the control device and the values were fixed to $50 \mathrm{~Hz}$ and $0.00010 \mathrm{~m}$, respectively. At the measuring time, the vibration was stopped and the particle bed heights (interior and annulus of the inner tube) were measured. The diameter of inner tube and the vibration conditions were changed in this experiment and the results were compared with the calculation results. The calculation results were in good agreement with the experimental data for all of the experiments. The example of the comparison between experimental data and calculated results are shown in Fig. 5.

\section{Results and Discussions}

\subsection{Bed height difference between the interior and annulus of inner tube}

When the particle bed with the inner tube is vibrated, a bed height difference is observed between the interior and annulus of the inner tube, as shown in Fig. 4. In this study, this difference is defined by using the following equation:

$$
\varphi_{B}=\frac{H_{I T}}{H_{0}},
$$


where $H_{\mathrm{IT}}$ indicates the particle bed height at the interior of the inner tube. When $H_{\mathrm{IT}}$ is higher than the bed height at the annulus, the value of $\varphi_{\mathrm{B}}$ is higher than 1.0. In contrast, when the value of $H_{\text {IT }}$ is less than the initial bed height $H_{0}$, i.e., when the bed height inside the inner tube is lower than that at the annulus, the value of $\varphi_{\mathrm{B}}$ is lower than 1.0.

The calculated results are compared with the experimental data shown in Fig. 5. This figure shows the change in the bed height difference between the interior and annulus of the inner tube $\varphi_{\mathrm{B}}$ with time. The amplitude and frequency of vibration are $0.0010 \mathrm{~m}$ and $50 \mathrm{~Hz}$, respectively. At the start of the experiment (calculation), the value of $\varphi_{\mathrm{B}}$ is 1.0 and then it increases with time. The value of $\varphi_{\mathrm{B}}$ becomes constant and remains stable after $5 \mathrm{~s}$ in both cases. The constant value of $\varphi_{\mathrm{B}}$ obtained by our calculation is in good agreement with that obtained by experimentally. From a result, the validity of the calculation is confirmed. In this study, the constant value of $\varphi_{\mathrm{B}}$ is used as the calculation result of $\varphi_{\mathrm{B}}$.

Fig. 6 shows the relationship between the bed height difference between interior and annulus of the inner tube and vibration conditions. When the amplitude of vibration is larger than $1.0 \mathrm{~mm}$, the value of $\varphi_{\mathrm{B}}$ is almost constant with vibration conditions. In the case of $0.5 \mathrm{~mm}$ of amplitude, the value of $\varphi_{\mathrm{B}}$ becomes lower than the other cases and $\varphi_{\mathrm{B}}$ is 1.0 in the case of non-vibration, i.e., it is considered that the value of $\varphi_{\mathrm{B}}$ could not change (it kept at 1.0) when the extremely small vibration was added to the bed. In this study, the vibration conditions were fixed as the standard case $(A=0.0010 \mathrm{~m}, f=50 \mathrm{~Hz})$. In a part of calculation, the vibration conditions were changed (Figs. 14 and 15).

Fig. 7 shows the plot of $\varphi_{\mathrm{B}}$ against $\alpha$. The horizontal axis $\alpha$ shows the ratio of the cross section at the interior of the inner tube to that at its annulus $\left(=D_{\mathrm{i}}{ }^{2} /\left(D_{\mathrm{o}}{ }^{2}-D_{\mathrm{io}}{ }^{2}\right)\right)$. The opened key shows the imaginary case, i.e., there is no friction between particle and wall. In the case with friction (actual case), the value of $\varphi_{\mathrm{B}}$ increases with $\alpha$. For relatively large values of $\alpha$, the bed height at the interior of the inner tube is higher than that at the annulus; in contrast, the bed height inside the inner tube is lower than that at the annulus. From this 
observation, it is confirmed that the bed height difference between the interior and annulus of the inner tube is strongly affected by the ratio of the cross section at the interior of the inner tube to that at the annulus. When the value of $\alpha$ is larger than 0.8 , the value of $\varphi_{\mathrm{B}}$ decreases with $\alpha$. This is because the annulus of the inner tube becomes too narrow and the particles are difficult to move in this area. Further, only a small amount of particle exists in this area, and the effect of the particle motion of this area on the bed height of the interior of the inner tube becomes small. In this study, the following three different cases are considered. (A) is the case in which the bed height at the interior of the inner tube is higher than that at the annulus. (B) is the case in which the bed height difference is small. (C) is the case in which the bed height at the interior of the inner tube is lower than that at the annulus. When there is no friction between particle and wall, the value of $\varphi_{\mathrm{B}}$ approaches 1.0. From this, it is found that the friction between particle and wall is one of the important factors for the bed height difference in the bed. The details of these phenomena were also discussed in the section 4.2.

The pressure at the lower part of the bed is considered to be related to the amount of the bed height difference. The pressure at height $H_{\mathrm{B}}$ shown in Fig. 2 is calculated from the following equation, which is based on Janssen's equation:

(Interior of the inner tube)

$$
p_{\text {in }}=\frac{D_{i} \rho_{B} g}{4 K \mu_{f w}}\left\{1-\exp \left(-\frac{4 K \mu_{f w} h}{D_{i}}\right)\right\},
$$

(Annulus of the inner tube)

$$
p_{a n}=\frac{\left(D_{o}-D_{i o}\right) \rho_{B} g}{4 K \mu_{f w}}\left\{1-\exp \left(-\frac{4 K \mu_{f w} h}{D_{o}-D_{i o}}\right)\right\},
$$

where $\rho_{\mathrm{B}}$ is the apparent density of the bed, and $h$ is the distance between the top of the bed and the lower edge of the inner tube. The value of $K$ can be obtained by using the following equation:

$$
K=\left(1-\sin \theta_{i}\right) /\left(1+\sin \theta_{i}\right),
$$


where $\theta_{\mathrm{i}}$ is the angle of contact between the glass beads and the acrylic resin wall. The value of $\theta_{1}$ is $33.4^{\circ}$ in this study. Fig. 8 shows the plot of $\varphi_{\mathrm{B}}$ against the ratio of pressure at the interior of the inner tube to that at the annulus $\left(p_{\text {in }} / p_{\text {an }}\right)$. The calculation conditions are the same as those shown in Fig. 7. Two kinds of calculations are performed in Eqs. (18) and (19), i.e., the different values of $h$ are used in calculation. The opened key indicates the case that the initial value of $h$ (before vibration; $h=H_{0}-H_{\mathrm{B}}$ ) is used for the calculation, and the closed key indicates the case of the stable state after vibration. In both cases, the value of $\varphi_{\mathrm{B}}$ is obtained after vibration. When $p_{\mathrm{in}} / p_{\text {an }}$ is equal to 1.0 , the value of $\varphi_{\mathrm{B}}$ is equal to 1.0 in both the cases. On the basis of this result, it is confirmed that the bed height difference does not occur when the pressure at the interior of the inner tube is equal to that at the annulus at the initial state. The bed height is stable, although $p_{\text {in }}$ is not equal to $p_{\text {an }}$ even after the vibration. In this case, the pressure is nonuniform in the particle bed. The particle motion in the bed is restricted by the friction between particle and wall as shown in Fig. 7. The particles are pushed up when the vessel moves upward, and they fall down when the vessel moves downward. This phenomenon repeats in the bed. In the area where the restriction by the friction is relatively strong (where the particles are easy to contact with the wall), the particle motion becomes small, thereby resulting in the bed height difference.

Fig. 9 shows the plot of $\varphi_{\mathrm{B}}$ against the ratio of the height of the bottom area $H_{\mathrm{B}}$ to the diameter of the particle $d_{\mathrm{p}}$. The three different conditions ((A), (B), and (C)) shown in Fig. 7 are considered in this figure. As the value of $H_{\mathrm{B}} / d_{\mathrm{p}}$ increases, the values of $\varphi_{\mathrm{B}}$ approach 1.0, i.e., the bed height difference decreases. The particles near the lower part of the bed can move easily when the value of $H_{\mathrm{B}} / d_{\mathrm{p}}$ is large. As the value of $H_{\mathrm{B}} / d_{\mathrm{p}}$ increases, the vibrational energy propagates with great difficulty to the upper part of the bed; therefore, the effect of the vibration on the particle motion becomes increasingly small. As a result, the bed height difference decreases with an increase in the value of $H_{\mathrm{B}} / d_{\mathrm{p}}$ in the bed. 


\subsection{Circulation of particles in vibrated bed with inner tube}

Fig. 10 shows the area of the circulation of particles under consideration in the vibrated bed with an inner tube. The upper part of the inner tube was cut, and the position of the upper edge of the inner tube was adjusted to the initial bed height. The average particle velocity inside the inner tube was considered as the circulation velocity of the particles. The averaged area of particle velocity is shown in this figure.

Fig. 11 shows the snapshots of the particle configurations in the vibrated bed with an inner tube. In order to clearly observe the circulation of particles in the bed, red-colored (upper part) and blue-colored (lower part) glass beads were used. In the case of (A), the value of $\varphi_{\mathrm{B}}$ is higher than 1.0. Hence, the particle circulates in the upward direction inside the inner tube. When the value of $\varphi_{\mathrm{B}}$ is almost equal to $1.0(\mathrm{~B})$, the circulation of the particles is not observed. The particle circulates in the downward direction inside the inner tube when the value of $\varphi_{\mathrm{B}}$ is less than 1.0 (C). These circulation directions are in good agreement with those predicted from the value of $\varphi_{\mathrm{B}}$. From these results, we confirm that the direction of particle circulation is dependent on the value of $\varphi_{\mathrm{B}}$.

Fig. 12 shows the velocity fields of particles in the vibrated bed in cases of (A) and (C) in Fig. 11. At first, case (A) is discussed. The collision between particles and bottom of the vessel occurs in (a) and (e). When the vessel moves upwards, the particles push up (b). Near the vessel wall and the inner tube, the particle motion is governed by the friction between particle and wall. Therefore the particles in the center of the bed move upwards more easily than in annulus of the inner tube. From the results, the particles in the bottom of the bed flow into the inside of the inner tube. When the vessel moves downwards, the particles also move downwards with the vessel (c), (d). The space appears in the bottom of the bed and the particles flow into there. In this case, however, the particles in the center of the bed still move upwards, and the particles in the annulus of the inner tube flow into the bottom of the bed (especially (c)). From the results, the circulation of particles in vibrated 
bed occurs. In the case of (C), in contrast, the particle motion in the inside of the inner tube is restricted by the friction. When the vessel moves upwards, the particles in the annulus of particles are easy to rise and the reverse circulation occurs (b). It is also confirmed that the particle circulation occurs when the vessel moves upwards.

Fig. 13 shows the relationship between the particle velocity inside of the inner tube and the amount of the bed height difference between the interior and annulus of the inner tube. The particle velocity was considered and averaged in the calculation area, as shown in Fig. 10. In the upward direction, the particle velocity is considered to be positive. The value of $\varphi_{\mathrm{B}}$ was adjusted by changing the diameter of the inner tube. When the value of $\varphi_{\mathrm{B}}$ is lower than about 0.75 , the particle velocity inside the inner tube is negative. This implies that the particles inside the inner tube move downwards. In contrast, the particles move upwards inside the inner tube when the value of $\varphi_{\mathrm{B}}$ is higher than about 1.25. The particle velocity increases with $\varphi_{\mathrm{B}}$. When the range of $\varphi_{\mathrm{B}}$ is from 0.75 to 1.25 , the particle velocity inside the inner tube is almost 0, i.e., the circulation of the particle can not be observed even if the value of $\varphi_{\mathrm{B}}$ is not 1.0. It is found that a certain degree of bed height difference is required for the circulation of particles. From this observation, it is confirmed that the amount of the bed height difference between interior of the inner tube and the annulus is related to the direction and velocity of particle circulation in the vibrated bed with the inner tube.

The effects of vibration conditions on the velocity of particle circulation in the bed are shown in Figs. 14 and 15. The determination method of particle velocity is the same as that in Fig. 13. The circulation direction does not change with vibration conditions. However, the particle velocity changes with vibration conditions. When the frequency and amplitude of vibration increase, the particle velocity becomes higher in cases of (A) and (C). The particle circulation appears when the vessel moves upwards, and the opportunity of particle circulation increases when the vibration frequency increases. Therefore, the velocity of particle circulation increases with vibration frequency. As the vibration amplitude 
increases, the space at the bottom of the bed increases and larger amounts of particles push up when the vessel moves upwards. From the results, it is found that the circulation velocity of particle changes with vibration conditions but the circulation direction does not change.

\section{Conclusions}

In this study, the particle motion in a vibrated bed with an inner tube was simulated by the DEM. The bed height difference between the interior and annulus of the inner tube was observed. When the inner tube is immersed in the bed, the bed height difference causes the circulation of particles in the bed. The effects of the bed height difference and the vibration conditions on the circulation velocity of particles were examined, and the following facts are obtained.

1. The ratio of the cross section inside the tube to that at the annulus strongly affects the bed height difference between the interior and annulus of the inner tube.

2. As the ratio of the height of the bottom area to the particle diameter increases, the amount of the height difference in the bed decreases.

3. The amount of bed height difference in the particle bed is related to the direction and velocity of the particle circulation in the vibrated bed with the inner tube.

4. The velocity of particle circulation changes with vibration conditions but the circulation direction does not change.

From this study, we concluded that the direction and velocity of particle circulation can be controlled by changing the inner tube diameter and the circulation velocity is also controlled with vibration conditions. 


\section{Symbol used}
A $[\mathrm{m}]$
amplitude
a [-]
coefficient of Eqs. (6) and (10)
$D_{\mathrm{i}} \quad[\mathrm{m}]$
inner diameter of the inner tube
$D_{\text {io }} \quad[\mathrm{m}]$
outer diameter of the inner tube
$D_{0} \quad[\mathrm{~m}]$
inner diameter of the vessel
$d \quad[\mathrm{~m}]$
diameter
$E \quad\left[\mathrm{~N} / \mathrm{m}^{2}\right]$
modulus of longitudinal elasticity
$f \quad[\mathrm{~Hz}]$
frequency of vibration
$f_{\mathrm{C}} \quad[\mathrm{N}]$
contact force
$G \quad\left[\mathrm{~N} / \mathrm{m}^{2}\right]$
modulus of transverse elasticity
$g \quad\left[\mathrm{~m} / \mathrm{s}^{2}\right]$
gravity acceleration
$H_{0} \quad[\mathrm{~m}]$
initial bed height
$H_{\mathrm{B}} \quad[\mathrm{m}]$
distance between bottom of vessel and lower edge of inner tube
$H_{\text {IT }} \quad[\mathrm{m}]$
bed height at interior of the inner tube
$h \quad[\mathrm{~m}]$
length between the lower edge of inner tube and the top of bed
I $\quad\left[\mathrm{kg} / \mathrm{m}^{2}\right]$
moment of inertia
K $[-]$
parameter of Eqs. (11) and (12)
$k_{\mathrm{n}} \quad\left[\mathrm{N} /\left(\mathrm{m}^{3 / 2}\right)\right]$
spring constant for normal direction
$k_{\mathrm{t}} \quad[\mathrm{N} / \mathrm{m}]$
spring constant for tangential direction
$m \quad[\mathrm{~kg}]$
mass of particle
$n \quad[-]$
unit vector
$p_{\text {in }} \quad[\mathrm{Pa}]$
pressure at interior of the inner tube
$p_{\text {an }} \quad[\mathrm{Pa}]$
pressure at annulus of the inner tube
$t \quad[\mathrm{~s}]$
time
$T \quad[\mathrm{~N} / \mathrm{m}]$
torque 
$\begin{array}{lll}v & {[\mathrm{~m} / \mathrm{s}]} & \text { velocity } \\ Z_{\mathrm{w}} & {[\mathrm{m}]} & \text { displacement of the vessel }\end{array}$

Greek symbols

$\alpha \quad[-] \quad$ ratio of cross section of the interior of the inner tube to that at its annulus $\left(=D_{\mathrm{i}}{ }^{2} /\left(D_{\mathrm{o}}{ }^{2}-D_{\mathrm{io}}{ }^{2}\right)\right)$

$\begin{array}{lll}\gamma & {[-]} & \text { Poisson's ratio } \\ \delta & {[\mathrm{m}]} & \text { displacement } \\ \Delta \mathrm{t} & {[\mathrm{s}]} & \text { time interval } \\ \eta & {[\mathrm{kg} / \mathrm{s}]} & \text { damping constant } \\ \theta_{\mathrm{I}} & {[\mathrm{rad}]} & \text { angle of contact } \\ \mu_{\mathrm{f}} & {[-]} & \text { coefficient of friction } \\ \rho_{\mathrm{B}} & {\left[\mathrm{kg} / \mathrm{m}^{3}\right]} & \text { apparent density of bed } \\ \varphi_{\mathrm{B}} & {[-]} & \text { amount of difference in bed height between the interior and annulus of }\end{array}$ the inner tube

$\omega \quad[1 / s] \quad$ angular velocity

\section{Subscripts}

i particle i

$\mathrm{j} \quad$ particle $\mathrm{j}$

n normal direction

p particle

t tangential direction

w wall 


\section{References}

[1] T. Akiyama, Y. Tsuruta, K. Aoki, Kagaku Kogaku Ronbunshu 1999, 25, 585.

[2] T. Akiyama, R. Nishiyama, Powder Technol. 1994, 80, 11.

[3] Y. Tatemoto, Y. Mawatari, Y. Yasukawa, K. Noda, Chem. Eng. Sci. 2004, 59, 437.

[4] P. A. Cundall, O. D. L. Srack, Geotechnique 1979, 29, 45.

[5] Y. Tsuji, T. Kawaguchi, T. Tanaka, Powder Technol. 1993, 77, 79.

[6] L. S. Lu, S. S. Hisau, Powder Technol. 2008, 184, 31.

[7] T. Tanaka, T. Ishida, Y. Tsuji, Nihon Kikai Gakkai Ronbunshu B-hen 1991, 57, 456.

[8] R. D. Mindlin, H. Deresiewicz,. Journal of Applied Mechanics 1953, 20, 327. 


\section{Figure Captions}

Figure 1. Model of contact force.

Figure 2. Calculation area.

Figure 3. Outline of experimental apparatus.

Figure 4. Definition of amount of difference in bed height between interior and annulus of inner tube.

Figure 5. Change in bed height difference between interior and annulus of inner tube with time.

Figure 6. Relationship between bed height difference between interior and annulus of inner tube and vibration conditions.

Figure 7. Plot of amount of difference in bed height between interior and annulus of inner tube against ratio of cross section of interior of inner tube to that at its annulus.

Figure 8. Plot of amount of difference in bed height between interior and annulus of inner tube against ratio of pressure at interior of inner tube to that at annulus.

Figure 9. Plot of amount of difference in bed height between interior and annulus of inner tube against ratio of height of bottom area to diameter of particle.

Figure 10. Area of circulation of particles under consideration in vibrated bed with inner tube.

Figure 11. Snapshots of particle configurations in vibrated bed with inner tube.

Figure 12. Velocity field of particles in vibrated bed with inner tube.

Figure 13. Relationship between particle velocity inside of inner tube and amount of difference in bed height between interior and annulus of inner tube.

Figure 14. Relationship between vibration frequency and particle velocity inside of inner tube.

Figure 15. Relationship between vibration amplitude and particle velocity inside of inner tube. 


\section{Equations}

$$
\begin{aligned}
& m \frac{d v_{\mathrm{p}}}{d t}=f_{\mathrm{C}}-m g \\
& f_{\text {Cnij }}=\left(-k_{\mathrm{n}} \delta_{\mathrm{nij}}^{3 / 2}-\eta_{\mathrm{n}} v_{\mathrm{rij}} \cdot n_{\mathrm{ij}}\right) n_{\mathrm{ij}} \\
& f_{\mathrm{Ctij}}=-k_{\mathrm{t}} \delta_{\mathrm{tij}}-\eta_{\mathrm{t}} v_{\mathrm{tij}} \\
& k_{n}=\frac{\sqrt{d_{p}} E_{p}}{3\left(1-\gamma_{p}^{2}\right)}, \\
& k_{t}=\frac{2 \sqrt{d_{p}} G_{p}}{2-\gamma_{p}} \delta_{n}^{1 / 2}, \\
& \eta_{n}=a \sqrt{m k_{n}} \delta_{n}^{1 / 4} \\
& \eta_{t}=\eta_{n} \\
& k_{n}=\frac{4}{3}\left(\frac{1-\gamma_{p}^{2}}{E_{p}}+\frac{1-\gamma_{w}^{2}}{E_{w}}\right)^{-1} \sqrt{\frac{d_{p}}{2}}, \\
& k_{t}=\frac{2 \sqrt{d_{p}} G_{p}}{2-\gamma_{p}} \delta_{n}^{1 / 2}, \\
& \eta_{n}=a \sqrt{m k_{n}} \delta_{n}^{1 / 4} \\
& \eta_{t}=\eta_{n} \\
& G=\frac{E}{2(1+\gamma)} \\
& \text { If }\left|f_{\text {Ctij }}\right|>\mu_{\mathrm{f}}\left|f_{\text {Cnij }}\right| \text {, then } f_{\text {Ctij }}=\mu_{\mathrm{f}}\left|f_{\text {Cnij }}\right| \frac{v_{\text {tij }}}{\left|v_{\text {tij }}\right|} \\
& \mu_{\mathrm{f}}=\tan \theta_{\mathrm{i}}, \\
& \frac{d \omega_{\mathrm{p}}}{d t}=\frac{T}{I} \\
& z_{\mathrm{w}}=A \sin (2 \pi f t) \\
& \varphi_{\mathrm{B}}=\frac{H_{\mathrm{IT}}}{H_{0}} \\
& p_{\text {in }}=\frac{D_{\mathrm{i}} \rho_{\mathrm{B}} g}{4 K \mu_{\mathrm{fw}}}\left\{1-\exp \left(-\frac{4 K \mu_{\mathrm{fw}} h}{D_{\mathrm{i}}}\right)\right\} \\
& p_{\mathrm{an}}=\frac{\left(D_{\mathrm{o}}-D_{\mathrm{io}}\right) \rho_{\mathrm{B}} g}{4 K \mu_{\mathrm{fw}}}\left\{1-\exp \left(-\frac{4 K \mu_{\mathrm{fw}} h}{D_{\mathrm{o}}-D_{\mathrm{io}}}\right)\right\}
\end{aligned}
$$


$K=\left(1-\sin \theta_{\mathrm{i}}\right) /\left(1+\sin \theta_{\mathrm{i}}\right)$, 
Table 1. Calculation conditions.

Particle (spherical glass beads) and wall and inner tube (acrylic resin)

Number of particle 5000

Particle density, $\rho_{\mathrm{p}}$ $2468 \mathrm{~kg} / \mathrm{m}^{3}$

Particle diameter, $d_{\mathrm{p}}$ $4.0 \mathrm{~mm}$

Restitution coefficient, $\alpha$

(particle - particle) $\quad 0.90$

(particle - wall) $\quad 0.90$

Friction coefficient

(particle-particle), $\mu_{\mathrm{fp}} \quad 0.509$

(partricle-wall), $\mu_{\mathrm{fw}} \quad 0.660$

Modulus of longitudinal elasticity
(particle), $E_{\mathrm{p}}$
$8.0 \times 10^{9} \mathrm{~N} / \mathrm{m}^{2}$
(wall), $E_{\mathrm{w}}$
$0.3 \times 10^{9} \mathrm{~N} / \mathrm{m}^{2}$

Poisson's ratio

$\begin{array}{ll}\text { (particle), } \gamma_{\mathrm{p}} & 0.23 \\ \text { (wall), } \gamma_{\mathrm{w}} & 0.39\end{array}$

Others

Initial bed height, $H_{0} \quad 0.075 \mathrm{~m}$

Time step of calculation, $\Delta t \quad 2.0 \times 10^{-6} \mathrm{~s}$ 


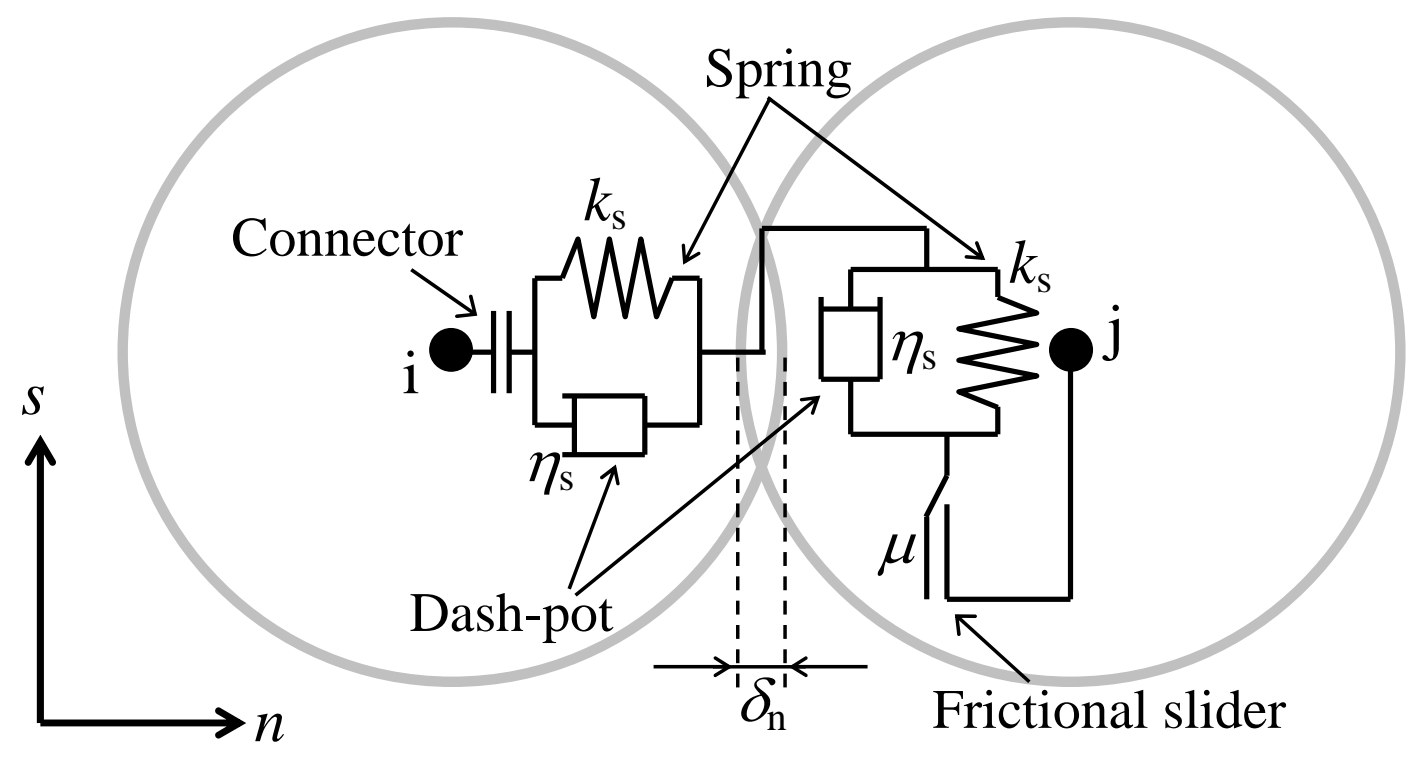

Figure 1. Model of contact force. 


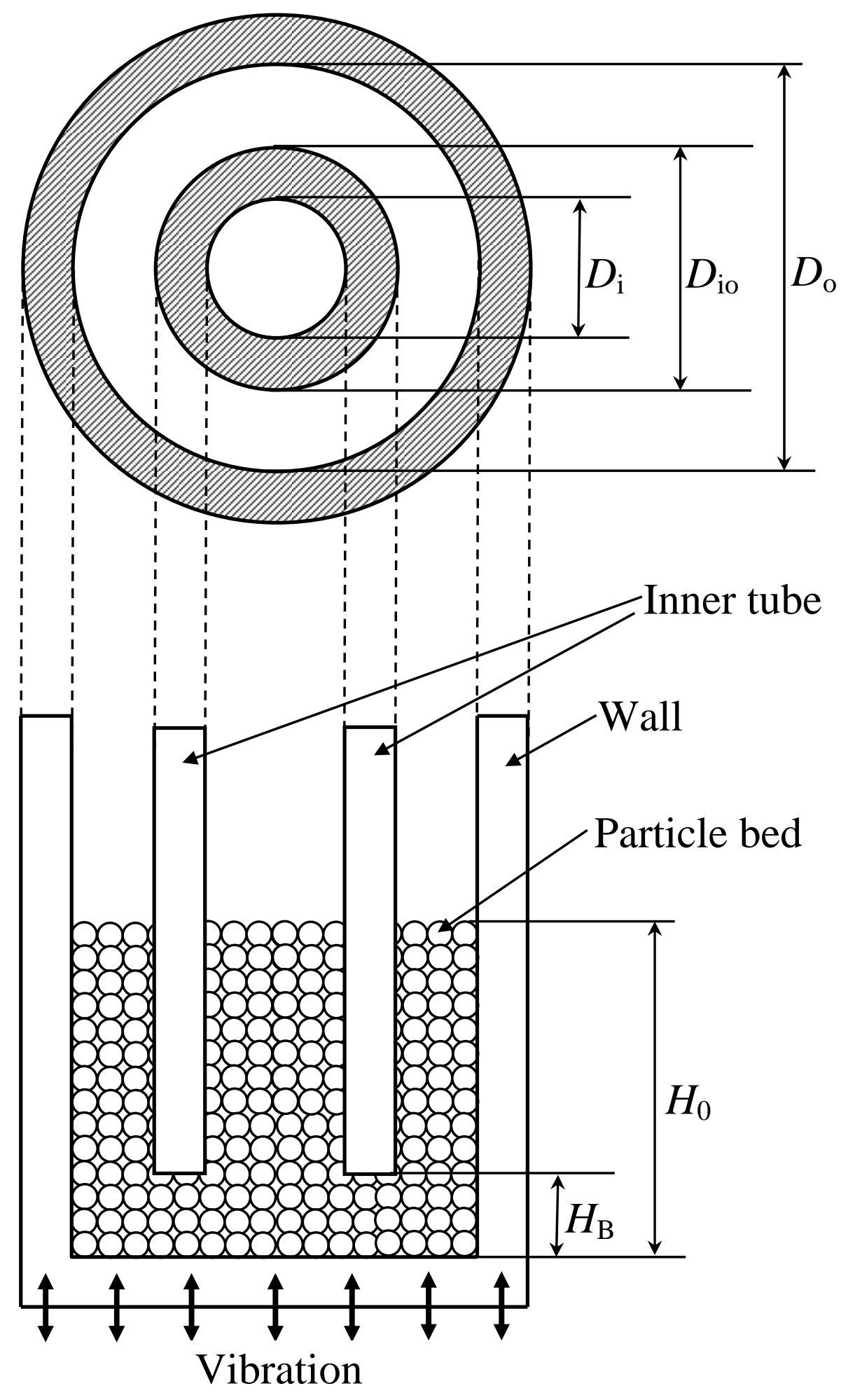

Figure 2. Calculation area.

Tatemoto et al. 


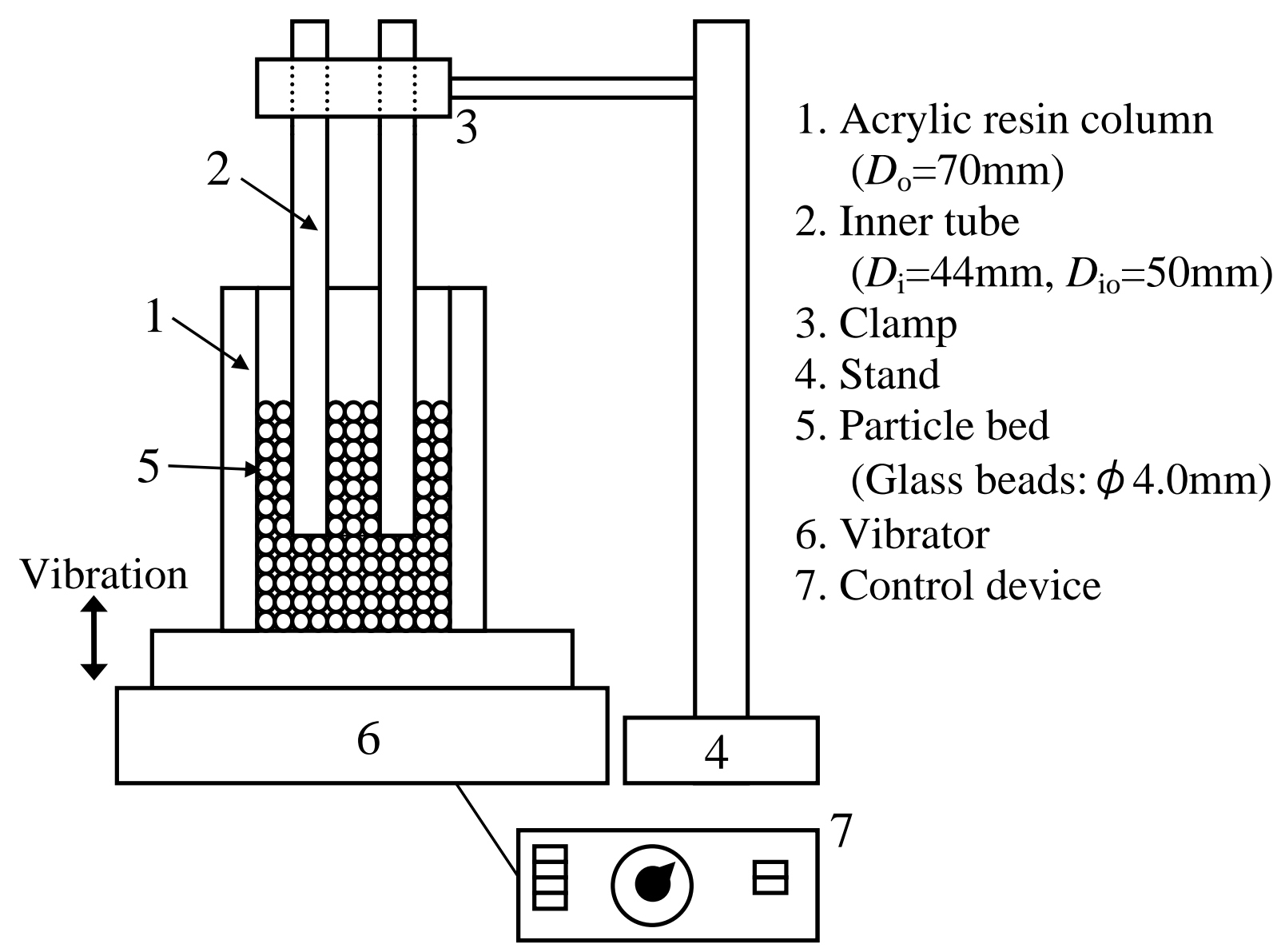

Figure 3. Outline of experimental apparatus. 


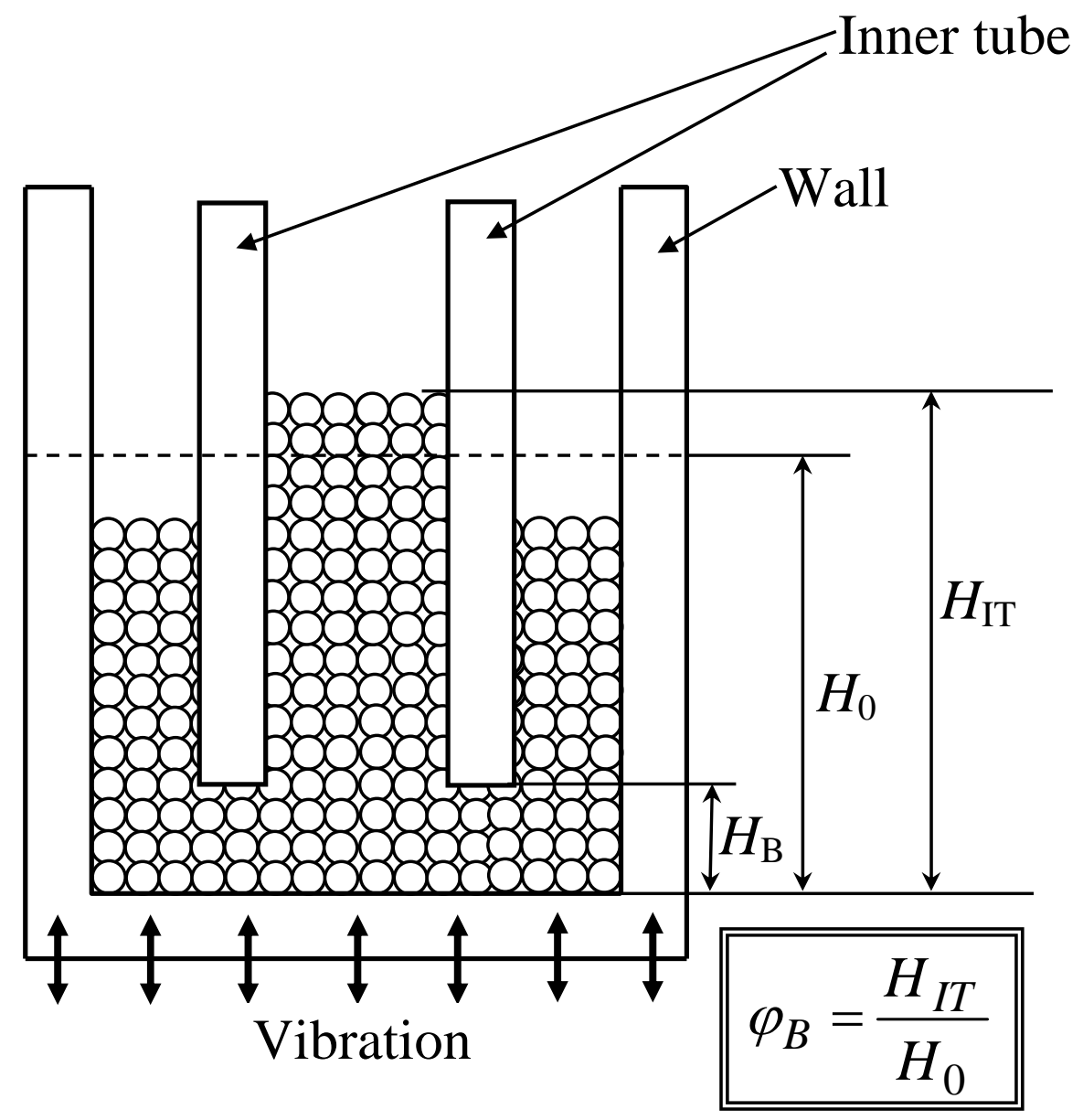

Figure 4. Definition of amount of difference in bed height between interior and annulus of inner tube.

Tatemoto et al. 


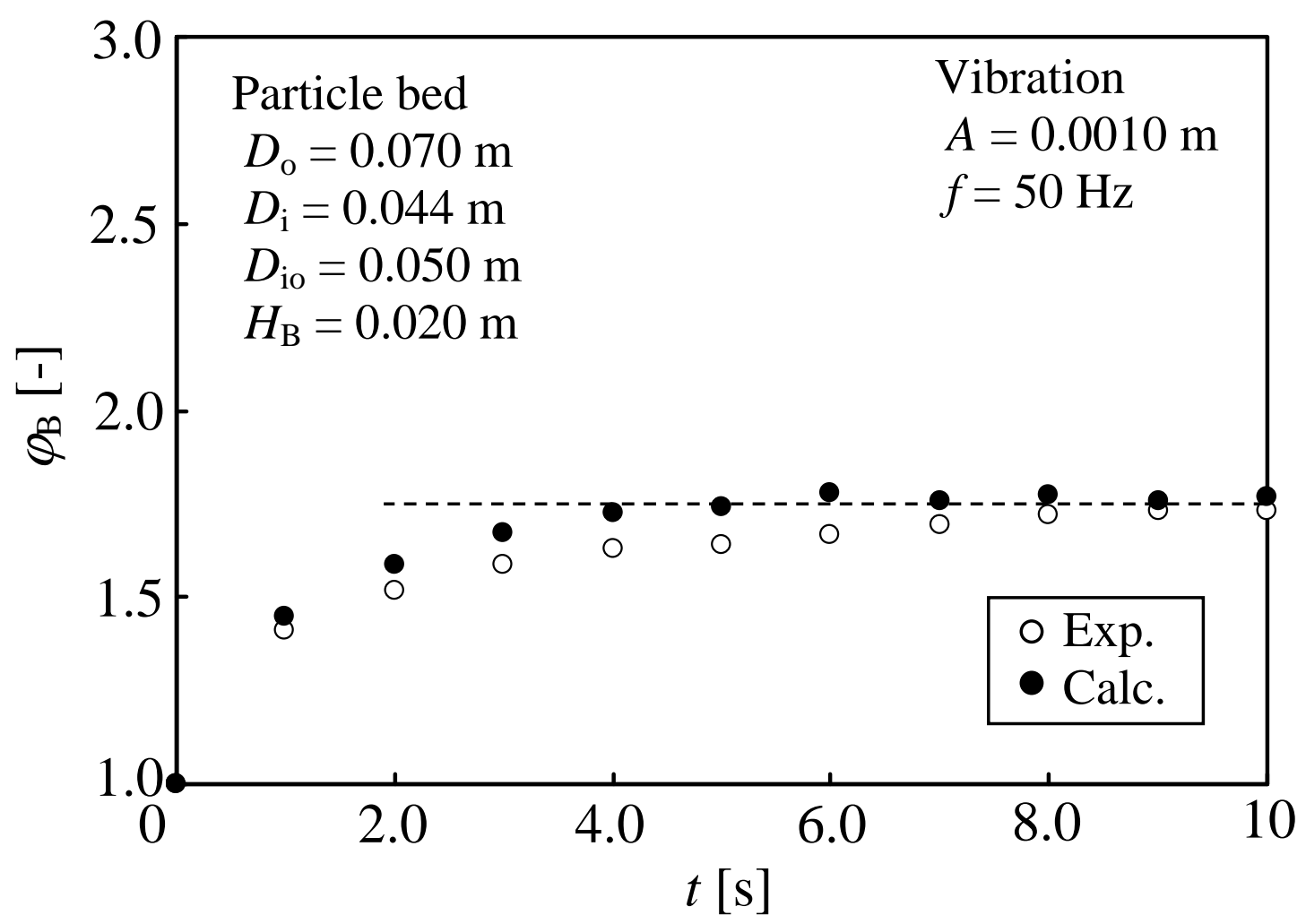

Figure 5. Change in bed height difference between interior and annulus of inner tube with time. 


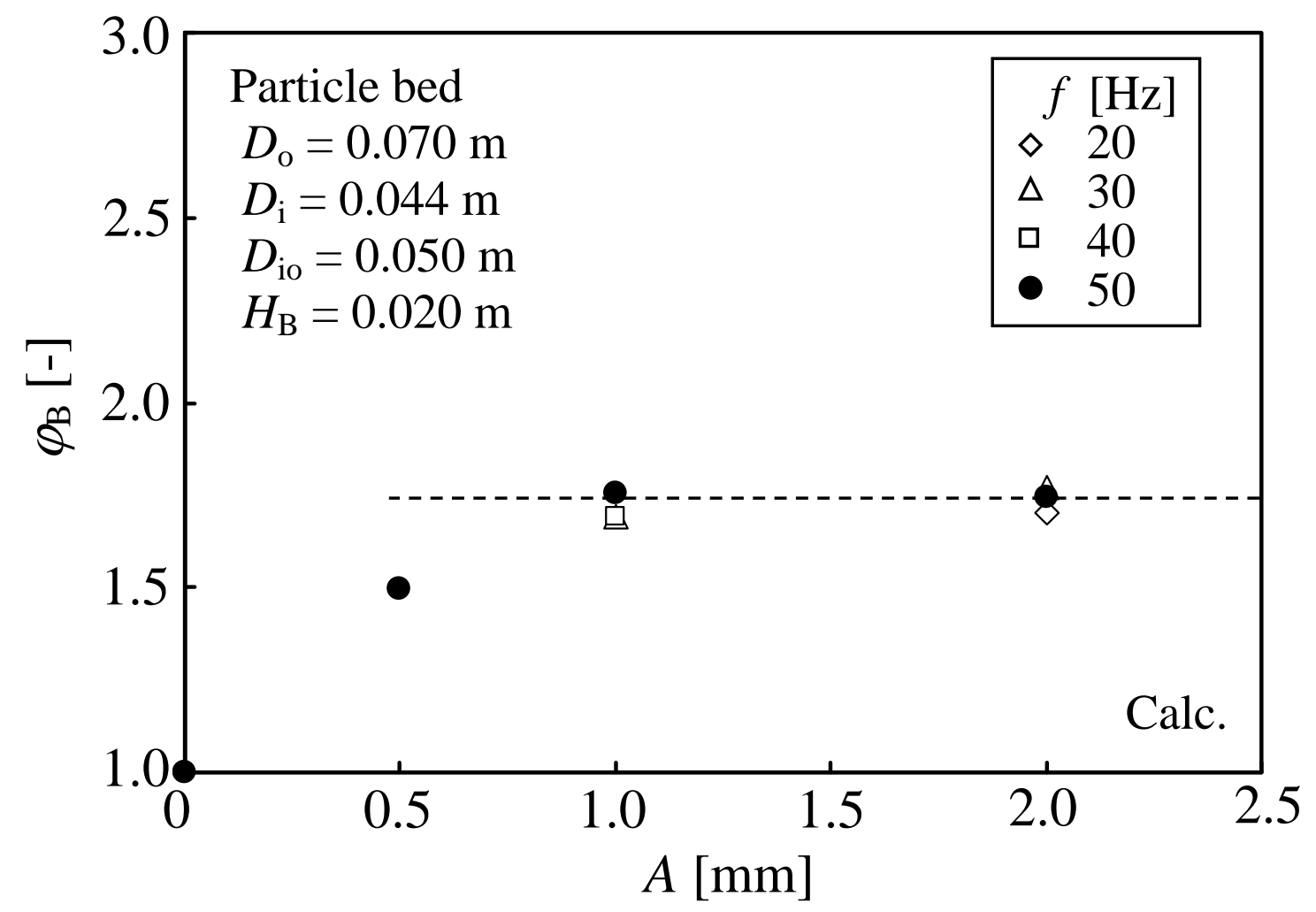

Figure 6. Relationship between bed height difference between interior and annulus of inner tube and vibration conditions. 
- With friction between particles and wall

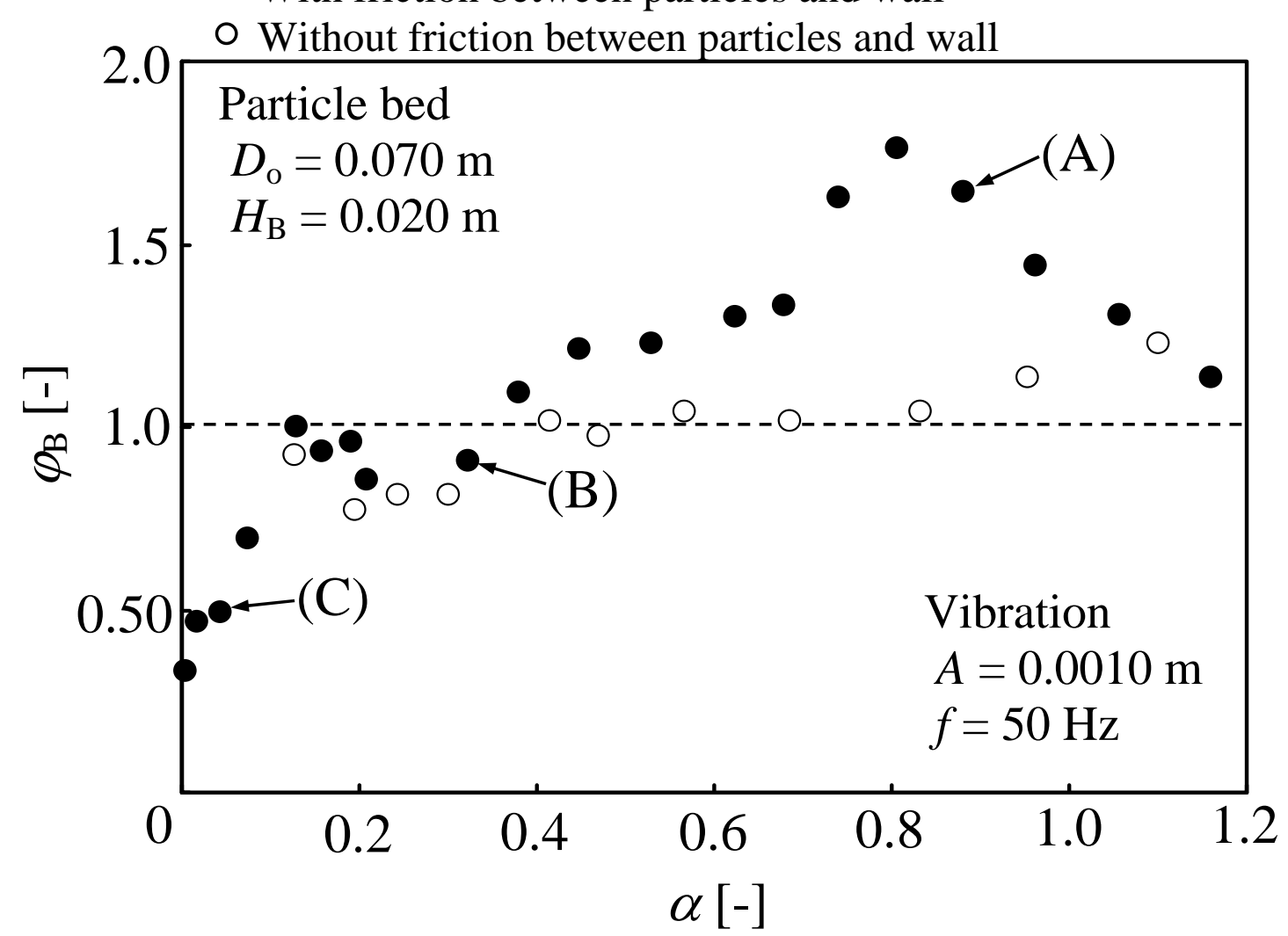

Figure 7. Plot of amount of difference in bed height between interior and annulus of inner tube against ratio of cross section of interior of inner tube to that at its annulus. 


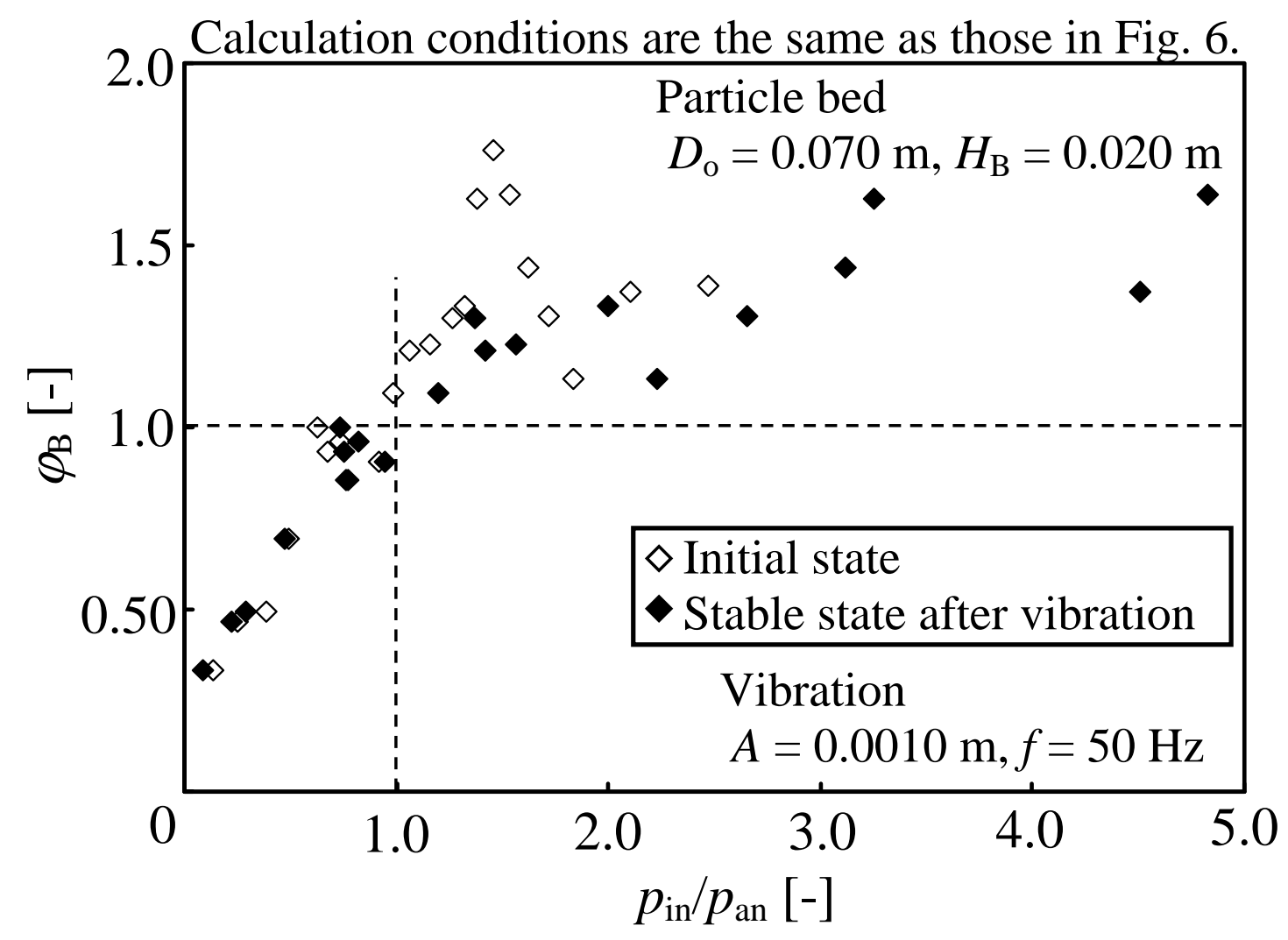

Figure 8. Plot of amount of difference in bed height between interior and annulus of inner tube against ratio of pressure at interior of inner tube to that at annulus. 


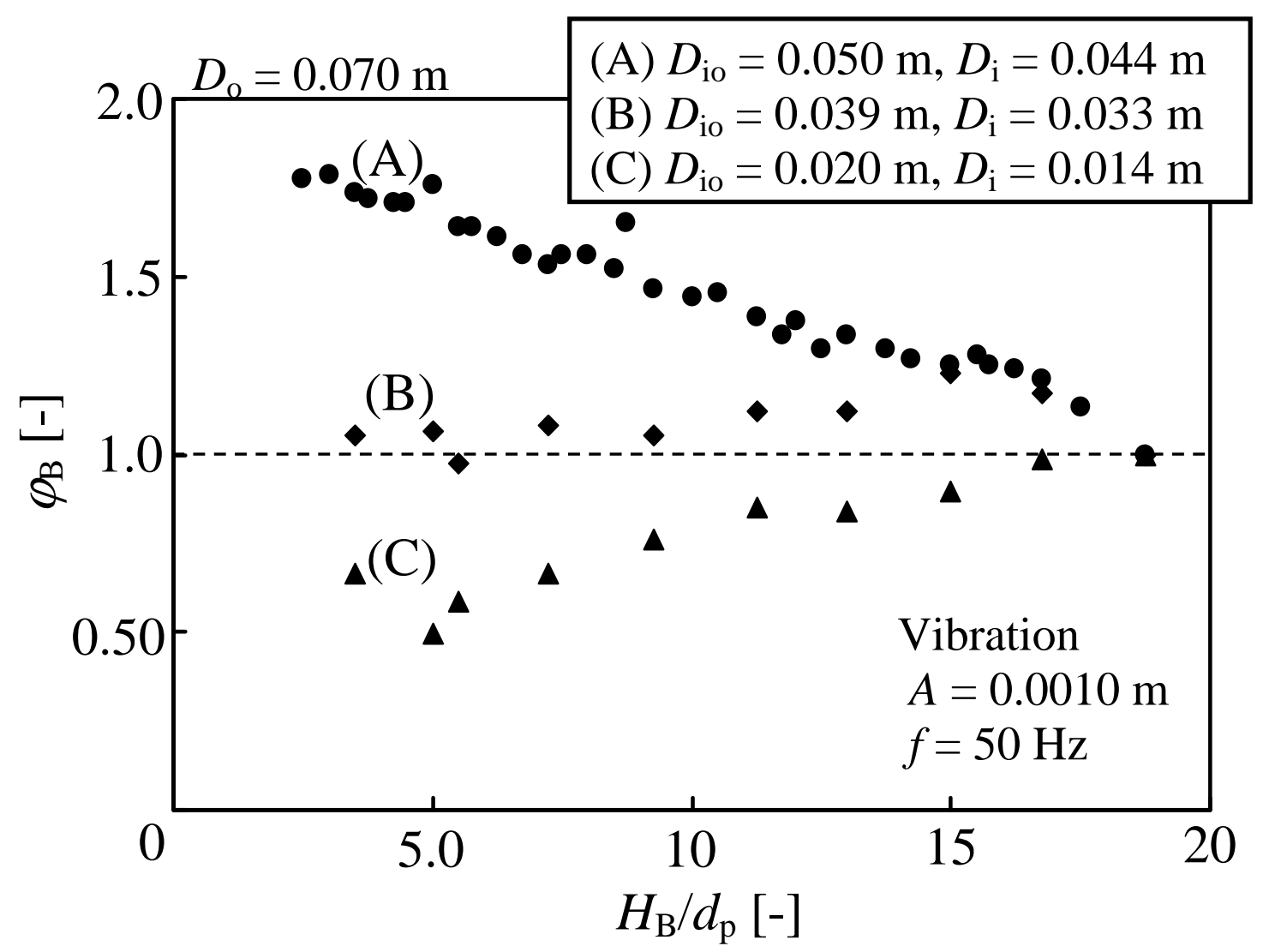

Figure 9. Plot of amount of difference in bed height between interior and annulus of inner tube against ratio of height of bottom area to diameter of particle. 


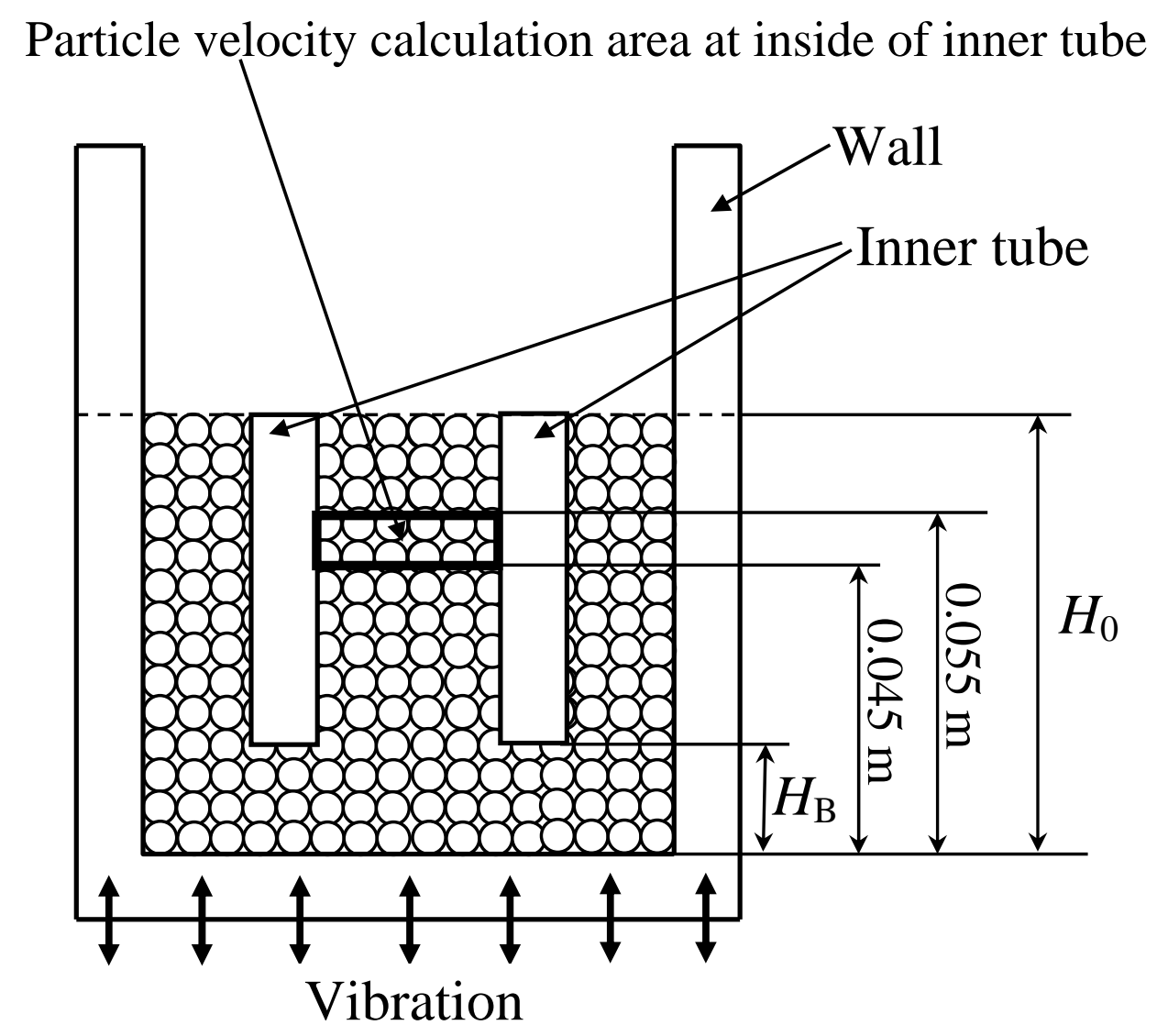

Figure 10. Area of circulation of particles under consideration in vibrated bed with inner tube. 
Particle bed: $D_{\mathrm{o}}=0.070 \mathrm{~m}, H_{\mathrm{B}}=0.020 \mathrm{~m}$

Vibration: $A=0.0010 \mathrm{~m}, f=50 \mathrm{~Hz}$

(A) $\varphi_{\mathrm{B}}=1.76, D_{\text {io }}=0.050 \mathrm{~m}, D_{\mathrm{i}}=0.044 \mathrm{~m}$

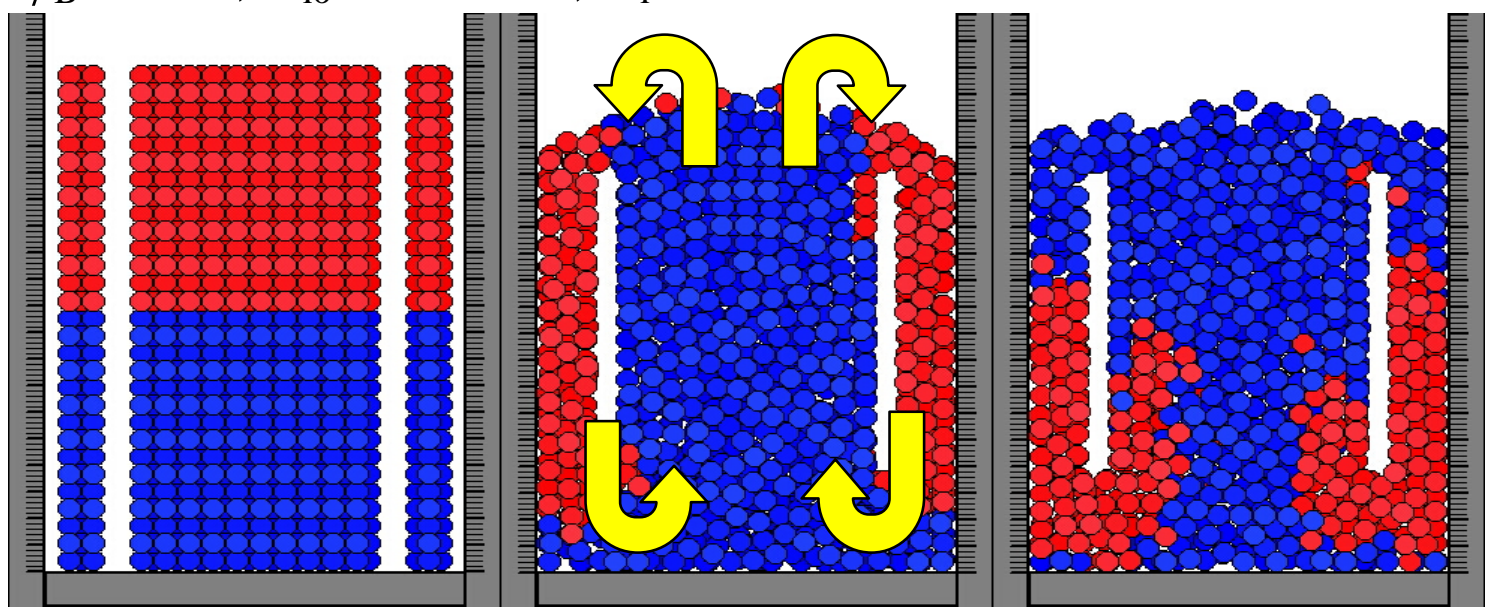

(B) $\varphi_{\mathrm{B}}=0.91, D_{\text {io }}=0.039 \mathrm{~m}, D_{\mathrm{i}}=0.033 \mathrm{~m}$

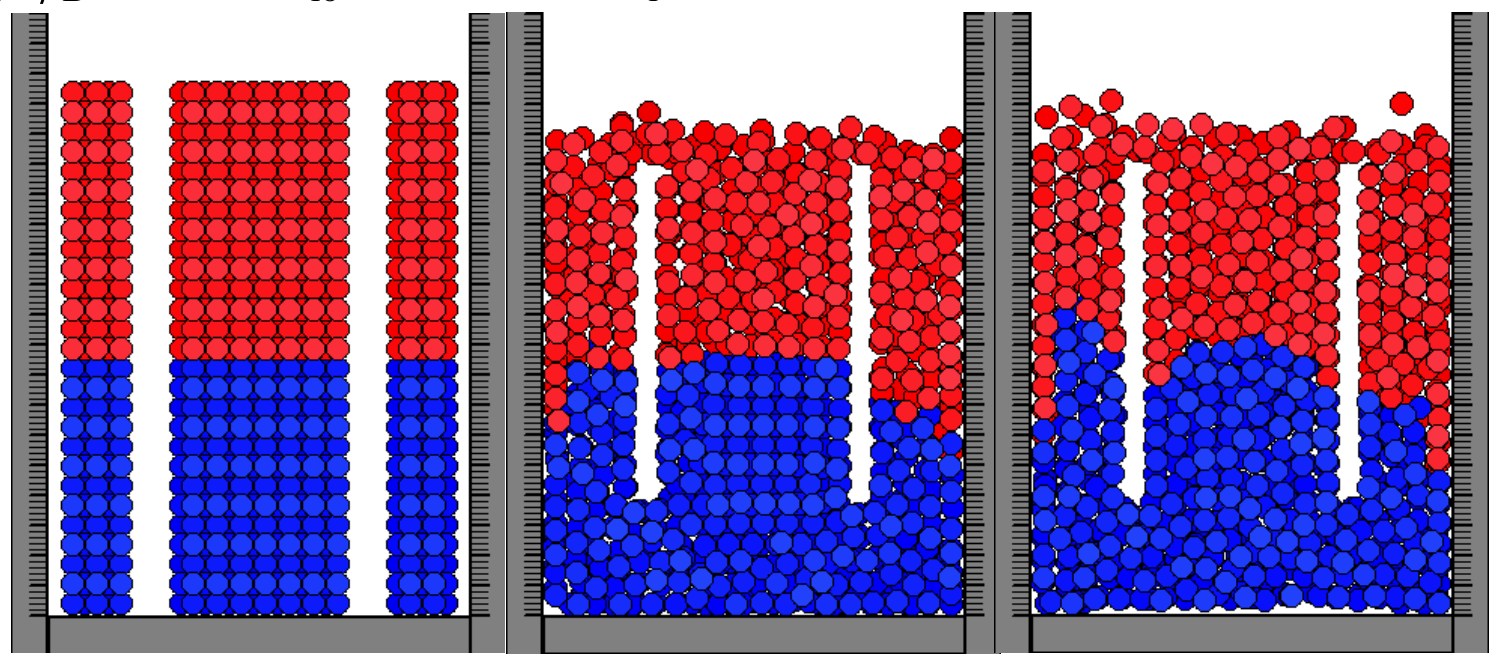

(C) $\varphi_{\mathrm{B}}=0.39, D_{\text {io }}=0.024 \mathrm{~m}, D_{\mathrm{i}}=0.018 \mathrm{~m}$

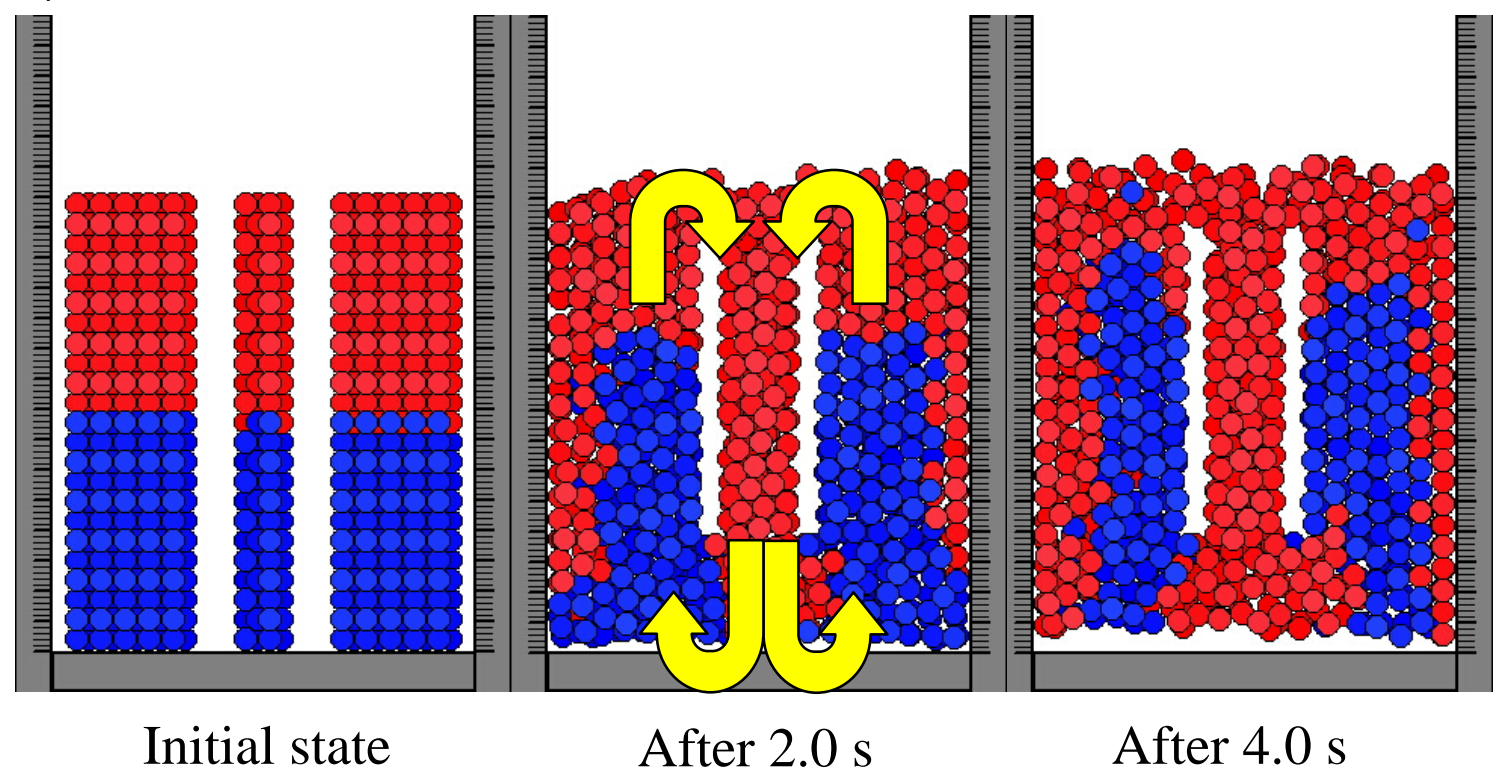

Figure 11. Snapshots of particle configurations in vibrated bed with inner tube.

Tatemoto et al. 
Particle bed: $D_{0}=0.070 \mathrm{~m}, H_{\mathrm{B}}=0.020 \mathrm{~m}$

(A) $\varphi_{\mathrm{B}}=1.76, D_{\mathrm{io}}=0.050 \mathrm{~m}, D_{\mathrm{i}}=0.044 \mathrm{~m}$

(a)

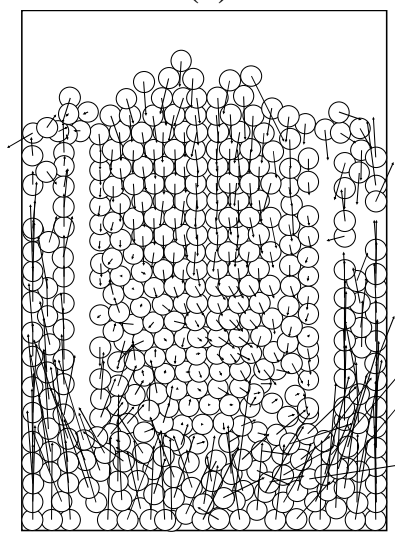

(b)

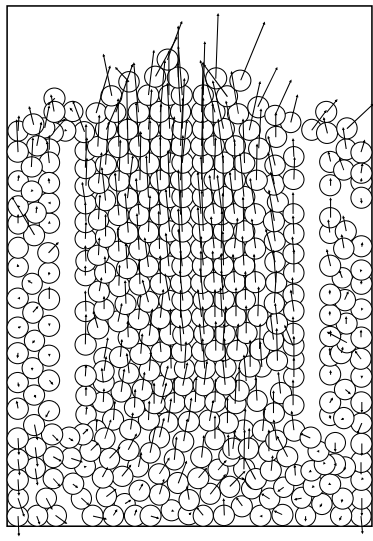

(C) $\varphi_{\mathrm{B}}=0.39, D_{\text {io }}=0.024 \mathrm{~m}, D_{\mathrm{i}}=0.018 \mathrm{~m}$

(a)

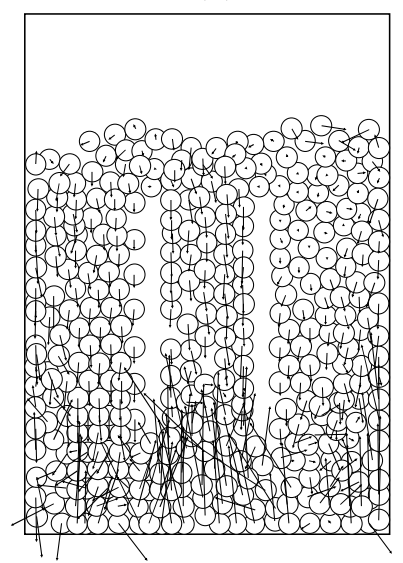

(c)

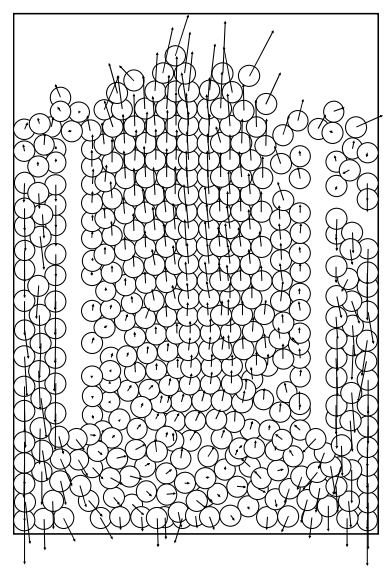

(c)

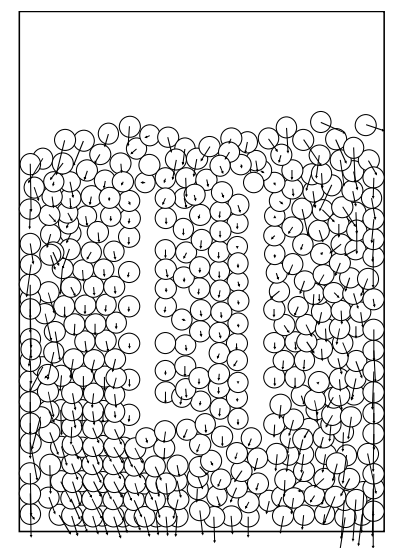

(d)

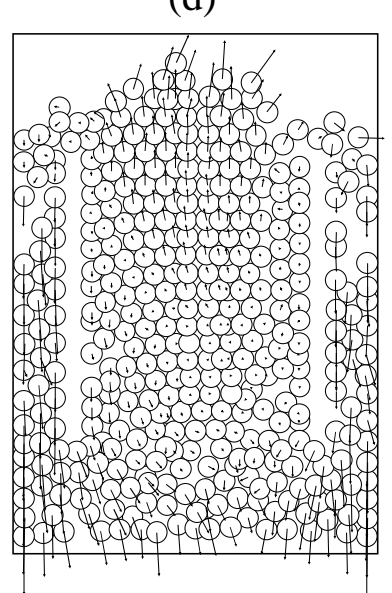

(d)

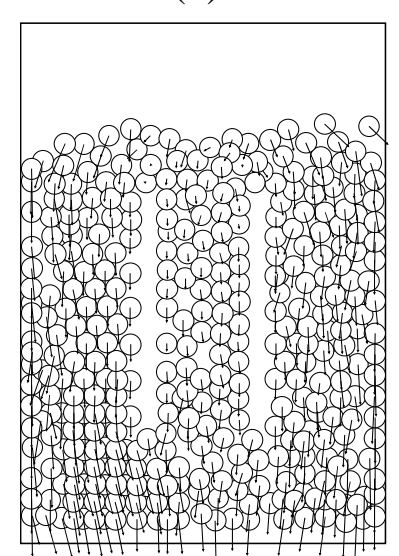

(e)

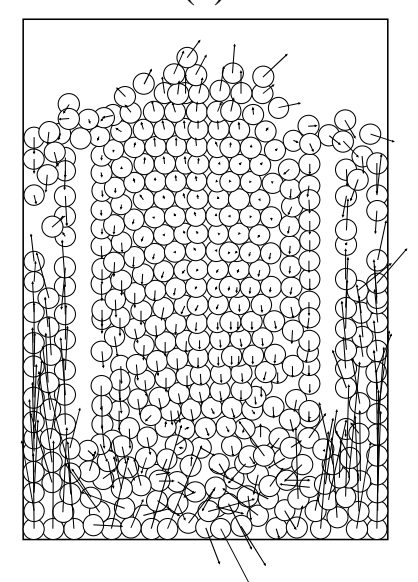

(e)

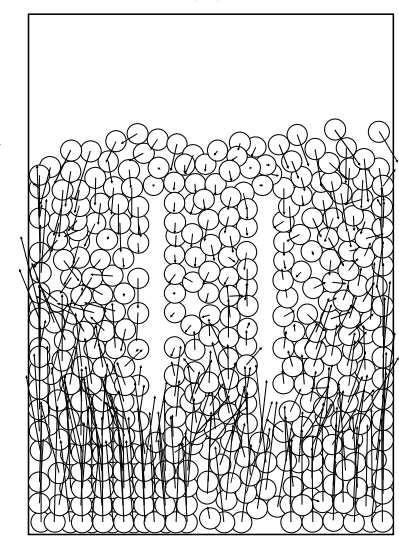

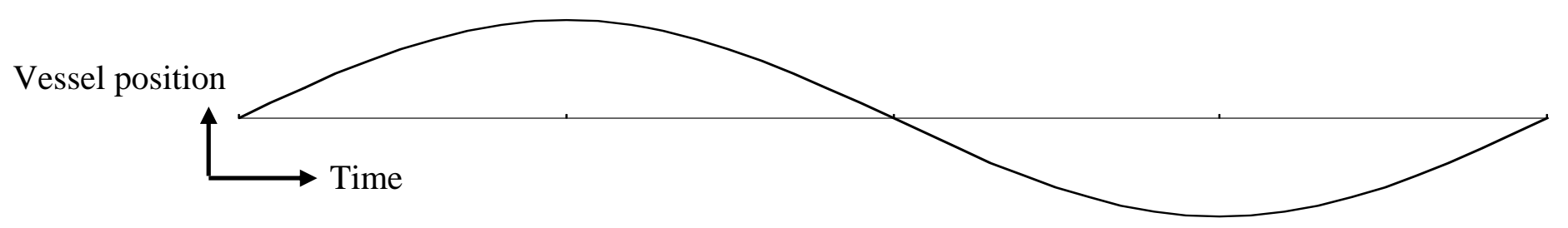

Figure 12. Velocity field of particles in vibrated bed with inner tube.

Tatemoto et al. 


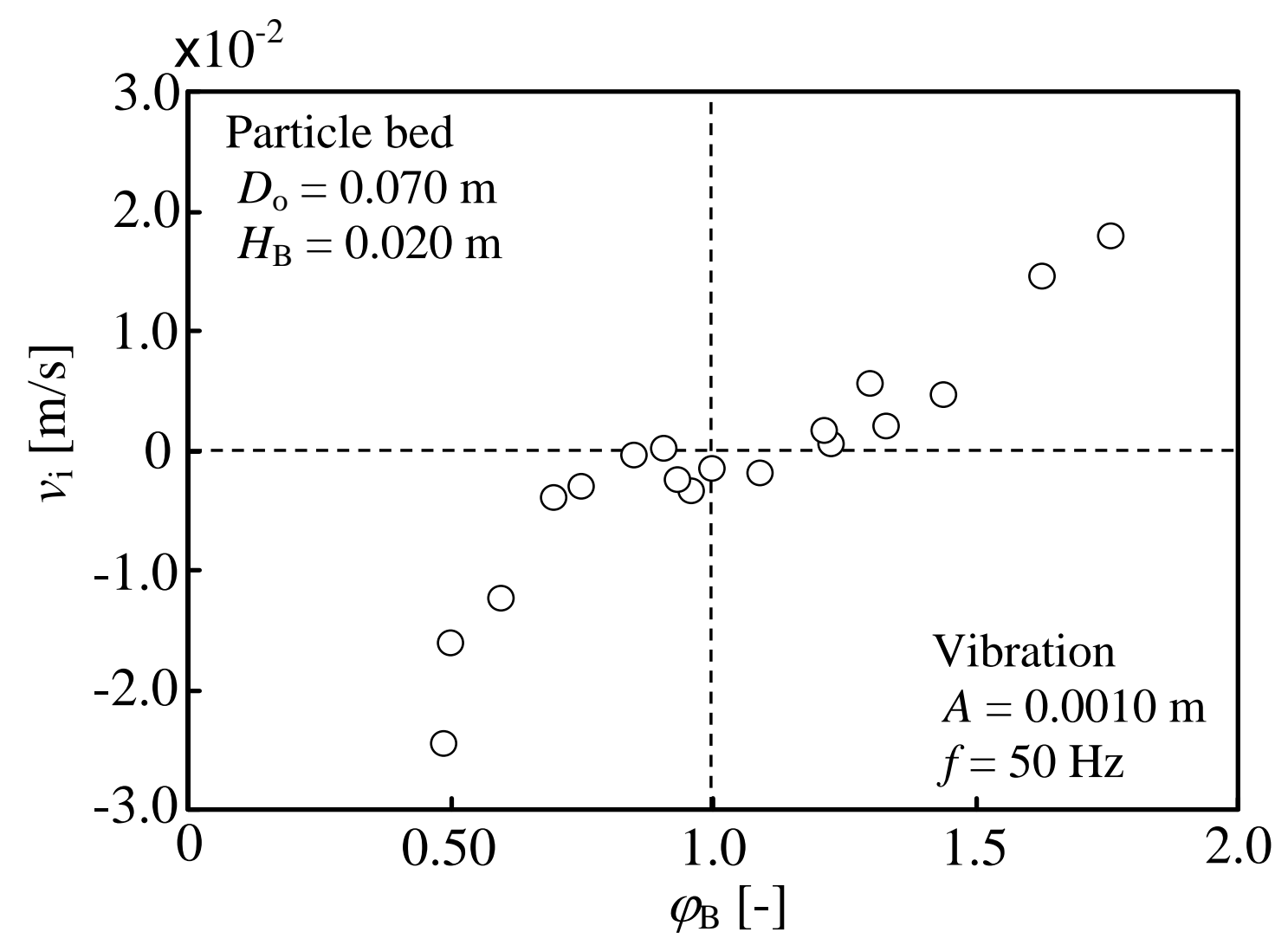

Figure 13. Relationship between particle velocity inside of inner tube and amount of difference in bed height between interior and annulus of inner tube. 


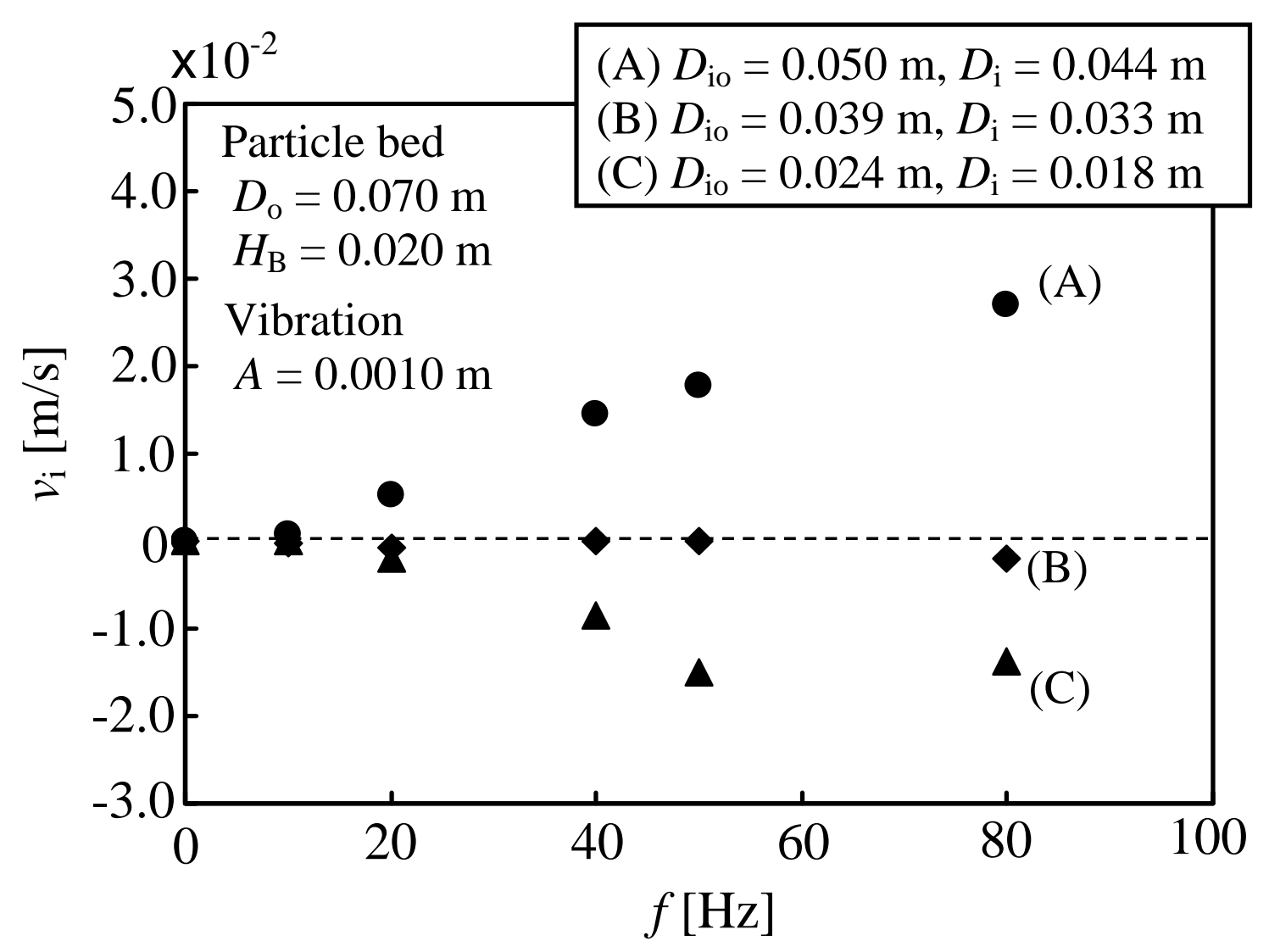

Figure 14. Relationship between vibration frequency and particle velocity inside of inner tube.

Tatemoto et al. 


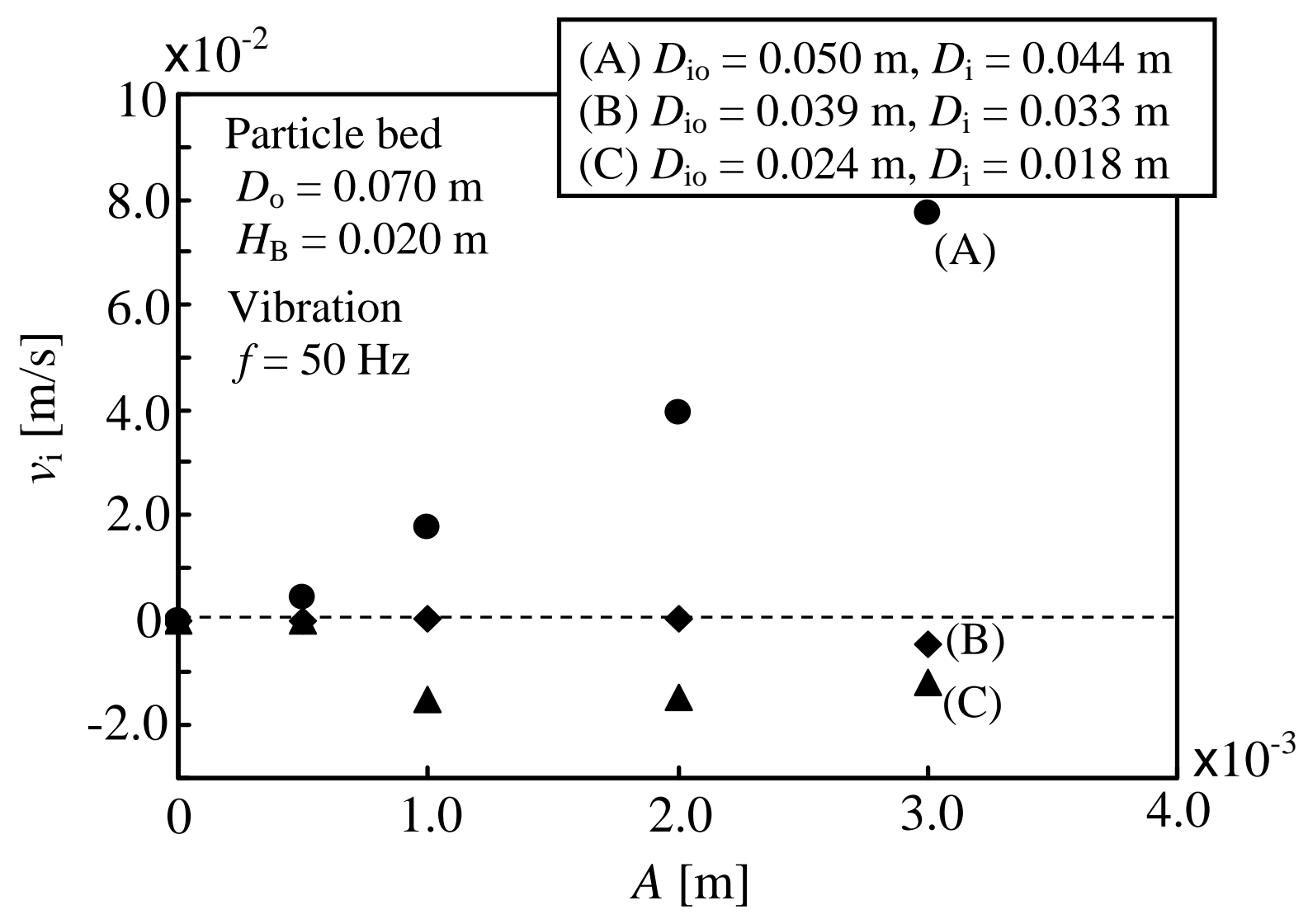

Figure 15. Relationship between vibration amplitude and particle velocity inside of inner tube. 